\title{
BMJ Open Dyslipidaemias in women using hormonal contraceptives: a cross sectional study in Mulago Hospital Family Planning Clinic, Kampala, Uganda
}

\author{
Ritah Bakesiima, ${ }^{1}$ Pauline Byakika-Kibwika, ${ }^{2}$ James K Tumwine, ${ }^{3}$ \\ Joan N Kalyango, ${ }^{1}$ Gloria Nabaasa, ${ }^{1}$ Irene Najjingo, ${ }^{1}$ Grace S Nabaggala, ${ }^{1}$ \\ Francis Olweny, ${ }^{1}$ Charles Karamagi ${ }^{3}$
}

To cite: Bakesiima R, ByakikaKibwika P, Tumwine JK, et al. Dyslipidaemias in women using hormonal contraceptives: a cross sectional study in Mulago Hospital Family Planning Clinic, Kampala, Uganda. BMJ Open 2018;8:e022338. doi:10.1136/ bmjopen-2018-022338

- Prepublication history for this paper is available online. To view these files, please visit the journal online (http://dx.doi. org/10.1136/bmjopen-2018022338).

Received 14 February 2018 Revised 27 August 2018 Accepted 26 September 2018

Check for updates

(c) Author(s) (or their employer(s)) 2018. Re-use permitted under CC BY-NC. No commercial re-use. See rights and permissions. Published by BMJ.

${ }^{1}$ Clinical Epidemiology Unit, School of Medicine, College of Health Sciences, Makerere University, Kampala, Uganda ${ }^{2}$ Department of Internal Medicine, School of Medicine, College of Health Sciences, Makerere University, Kampala, Uganda

${ }^{3}$ Department of Pediatrics and Child Health, School of Medicine, College of Health Sciences, Makerere University, Kampala, Uganda

Correspondence to Ritah Bakesiima; esmie.ritah@gmail.com

\section{ABSTRACT}

Objective To determine the prevalence and factors associated with dyslipidaemias in women using hormonal contraceptives.

Design Cross-sectional study

Setting Mulago Hospital, Kampala, Uganda

Participants Three hundred and eighty-four consenting women, aged 18-49 years, who had used hormonal contraceptives for at least 3 months prior to the study. Study outcome Dyslipidaemias (defined as derangements in lipid profile levels which included total cholesterol $\geq 200 \mathrm{mg} / \mathrm{dL}$, high-density lipoprotein $<40 \mathrm{mg} /$ $\mathrm{dL}$, triglyceride $>150 \mathrm{mg} / \mathrm{dL}$ or low-density lipoprotein $\geq 160 \mathrm{mg} / \mathrm{dL}$ ) for which the prevalence and associated factors were obtained.

Results The prevalence of dyslipidaemias was $63.3 \%$ (95\% Cl: 58.4 to 68.1). Body mass index (BMI) ( $P R=1.33$, $95 \% \mathrm{Cl}: 1.15$ to $1.54, \mathrm{p}<0.001)$ and use of antiretroviral therapy (ART) (PR=1.21, 95\% Cl: 1.03 to 1.42 , $p=0.020$ ) were the factors significantly associated with dyslipidaemias.

Conclusion Dyslipidaemias were present in more than half the participants, and this puts them at risk for cardiovascular diseases. The high-risk groups were women with a BMl greater than $25 \mathrm{Kg} / \mathrm{m}^{2}$ and those who were on ART. Therefore, lipid profiles should be assessed in women using hormonal contraceptives in order to manage them better.

\section{INTRODUCTION}

Globally, the use of contraception has risen slightly, from $54.7 \%$ in 1990 to $64 \%$ in $2015 .{ }^{1}$ In Uganda particularly, the contraceptive prevalence rate (CPR) is currently $27.2 \%$ with hormonal contraceptives (HCs) accounting for $77.9 \%$ of the total contraceptive use. ${ }^{1}$ Among the HCs used in Uganda, injectables are the most common $(72.8 \%)$, followed by oral contraceptives $(14.3 \%)$ and implants $(12.9 \%)^{2}$

\section{Strengths and limitations of the study}

- This is one of the first studies in Uganda to assess dyslipidaemias in women using hormonal contraceptives, hence providing baseline information.

- Standard approaches were used to carry out the study to ensure repeatability and reproducibility.

- Consecutive non-probability sampling was used so the results may not be generalisable to all hormonal contraceptive users.

- Since this was a cross-sectional study, a causal relationship between hormonal contraceptive use and dyslipidaemias could not be ascertained.

- The results may have been subject to information bias since questionnaires were used to obtain information on some variables based on recall.

Several researchers have reported the complications and side effects associated with the use of HCs. ${ }^{3-5}$ The side effects include nausea and vomiting, headaches, dizziness, breast tenderness and enlargement, irregular bleeding or bleeding between periods, and weight gain. The adverse effects include metabolism impairment, cardiovascular complications, and an increased risk of cancer and liver problems. ${ }^{3}$ It has been suggested that some of these complications are a consequence of dyslipidaemias, a potential metabolic impairment effect of long-term use of some HCs. ${ }^{5}$ Furthermore, a study by Schueller and colleagues suggested that dyslipidaemias could also arise from the hormones increasing apolipoprotein B-100 synthesis which subsequently increases triglyceride and Low Density Lipoprotein (LDL) levels. ${ }^{4}$

Several factors predispose $\mathrm{HC}$ users to dyslipidaemias. The factors include age, race, lifestyle and diseases such as hypertension 
and diabetes mellitus. Medications especially ART and steroids also contribute. ${ }^{5-9}$ Many of these factors are common in Uganda. For example, $16 \%$ of the women in Uganda were found to be obese. ${ }^{10}$ Obesity is associated with alterations in lipid profile levels. In the presence of $\mathrm{HC}$ use, obesity makes the risk of dyslipidaemias worse. ${ }^{67}$ In addition, $79 \%$ of all women with HIV infection of reproductive age in Uganda are on antiretroviral therapy (ART). ${ }^{11}$ Some antiretroviral drugs alter lipid profile levels, hence causing dyslipidaemias. ${ }^{12} 13$

Poorly managed dyslipidaemias can result into cardiovascular diseases such as venous thromboembolism, myocardial infarction and stroke. ${ }^{14}$ However, lipid profile levels are not routinely measured in women using HCs in Uganda. Therefore, the objective of this study was to determine the prevalence and factors associated with dyslipidaemias in women using HCs at Mulago Hospital Family Planning Clinic, Kampala in Uganda.

\section{METHODS}

\section{Study design, setting and population}

This was a cross-sectional study employing both descriptive and analytical techniques carried out from Mulago Hospital Family Planning Clinic in Uganda's Capital City, Kampala from March to April 2017. This clinic receives approximately 320 patients monthly, 215 of whom are on HCs. Using the consecutive sampling procedure, 384 consenting women aged 18-49 years were enrolled into this study. They had to have used HCs for at least 3 months prior to the study. Women who were unable to comprehend either English or Luganda (the local language used in Central Uganda) or those physically or mentally unable to adhere to study procedures such as giving of consent and the interview process, were excluded from the study.

\section{Sample size calculation}

The Leslie Kish formula ${ }^{15}$ was used to estimate the sample size for the prevalence objective. We assumed a prevalence of dyslipidaemias of $33.9 \%$ among women on oral contraceptives according to a study by Machado et al in Brazil $^{16}$ and $95 \%$ CIs. This gave a sample size of 345 . We also accounted for $10 \%$ missing data in the calculation of the sample size. Hence, the final sample size was 380 .

For the factors associated with dyslipidaemias, the formula for comparing means in two proportions ${ }^{17}$ was used. We assumed an error of 0.05 , power of $80 \%$ and $95 \%$ confidence level; and that $33.9 \%$ of women using oral contraceptives would develop dyslipidaemias compared with only $16.9 \%$ of those using non-oral contraceptives. We also assumed that the oral CPR in Uganda is $14.3 \%$. $^{2}$ This gave a sample size of 384 .

\section{Data collection}

A questionnaire was administered to collect basic information on age, parity, highest level of education, occupation, type of HC used, duration of use of HCs, use of antiretroviral drugs and history of hypertension. Body mass index (BMI) was determined by measuring weight using the Seca weighing scale and height using a Seca stadiometer. BMI was then computed as weight (in $\mathrm{kg}$ )/ height (in $\mathrm{m}^{2}$ ). Blood samples were aseptically collected from participants after a 6 -hour fast and placed in a red top vacutainer without an anticoagulant for the determination of lipid profile levels. The samples were allowed to clot for at least $3 \mathrm{~min}$ and centrifuged at 2400 revolutions/min for $5 \mathrm{~min}$. The serum obtained was pipetted into Cobas 6000 caps and taken for analysis using the Cobas 6000 chemistry analyser (Roche Diagnostics, USA). Fasting blood sugar levels were determined using a Freestyle glucometer (Abott Laboratories, Canada) for all the participants 6 hours after their last meal. A sterile single use lancet was used to prick the participant's disinfected finger and a small drop of the blood placed onto the glucometer strip already mounted into the glucometer. The blood sugar level was read off and recorded in $\mathrm{mg} / \mathrm{dL}$.

\section{Outcome variable}

The outcome variable for this study was dyslipidaemias defined as derangements in lipid profile levels which included a total cholesterol of $200 \mathrm{mg} / \mathrm{dL}$ or greater, a high-density lipoprotein cholesterol of less than $40 \mathrm{mg}$ / $\mathrm{dL}$, triglyceride of greater than $150 \mathrm{mg} / \mathrm{dL}$ or low-density lipoprotein cholesterol of $160 \mathrm{mg} / \mathrm{dL}$ or greater according to the Guidelines for the Diagnosis and Management of Dyslipidemias for Adults. ${ }^{18}$ A participant was said to have dyslipidaemias if he/she had any of the lipid profile parameters in ranges stated above. The presence of dyslipidaemias was coded as ' 1 ' and its absence as ' 0 '.

\section{Statistical analysis}

Data were analysed using STATA V.13.0 (StataCorp. 2013. Stata Statistical Software: Release 13) in which all continuous variables were summarised as medians and ranges while the categorical variables were summarised as percentages and proportions. The prevalence of dyslipidaemias was calculated as the percentage of women with dyslipidaemias over the total number of women in the study. The modified Poisson regression model was used to analyse the factors associated with dyslipidaemias in women using HCs. In the multivariate analysis, variables which were significantly associated with dyslipidaemias $(\mathrm{p}<0.05)$ were used to form two-way product terms that were used in the assessment of interaction using the chunk test. Where necessary, confounding was assessed for. Confounders were retained only if they changed the estimates by greater than or equal to $10 \%$. CIs were presented at $95 \%$ level of significance along with the $\mathrm{p}$ values. Statistical significance was considered at a $p$ value of less than or equal to 0.05 .

\section{Patient and public involvement}

Due to patients' experiences and concerns raised about excessive weight gain while on HCs, we felt the need to 
determine whether long-term use of HCs (more than 3 months) has an effect on lipid profile levels. Hence, patient experiences informed our research questions and study outcomes.

Patients were involved in the design of the study through their contribution to the refining of the data-collection tool. This was mainly during pretesting or piloting of the questionnaires. Results were disseminated to study participants through the use of text messages and fliers. The fliers, printed both in English and Luganda, were issued out at the family planning clinic.

\section{RESULTS}

\section{Participants' characteristics}

The median age of the 384 participants was 28 years (IQR: 18-49). An estimated 59.1\% (227/384) of the participants had attained only up to secondary education, $74.2 \%(285 / 384)$ had at least two or more children and $39.6 \%(152 / 384)$ were self-employed. Only $11(2.9 \%)$ had high fasting blood sugar levels $(\geq 120 \mathrm{mg} / \mathrm{dL}), 14$ $(3.7 \%)$ had a history of hypertension, $140(36.5 \%)$ had a BMI $>25$ and 78 (20.3\%) were on ART. Most of the participants $(48.2 \%)$ were using progestin-only injectables, and $219(57 \%)$ had used HCs for over a year (table 1$).$

\section{Prevalence of dyslipidaemias}

The prevalence of dyslipidaemias among the 384 participants was $63.3 \%$ (95\% CI: 58.4 to 68.1 ). Dyslipidaemias were higher in women aged above 28 years $(68.0 \%)$ compared with those who were younger. The prevalence of dyslipidaemias was also higher in participants who had attained up to tertiary education $(75 \%)$ than those who had acquired lower education. Furthermore, participants who had high fasting blood sugar levels $(\geq 120 \mathrm{mg} / \mathrm{dL})$ had more dyslipidaemias $(81.8 \%)$ than those who had normal blood sugar levels (table 2).

\section{Factors associated with dyslipidaemias}

Variables significantly associated with dyslipidaemias included BMI greater than $25 \mathrm{~kg} / \mathrm{m}^{2}(\mathrm{PR}=1.33,95 \%$ CI: 1.15 to $1.54, \mathrm{p}<0.001)$ and ART use ( $\mathrm{PR}=1.21,95 \% \mathrm{CI}: 1.03$ to $1.42, \mathrm{p}=0.020)$. These variables were further assessed for interaction between each other and for confounding with other independent variables. However, there was no interaction and the association between dyslipidaemias and these variables was not confounded by any other independent variables. Therefore, BMI and ART use were the only independent factors associated with dyslipidaemias (table 3).

\section{DISCUSSION}

Dyslipidaemias were present in more than half the participants. This high prevalence of dyslipidaemias could be an overestimate in the general population because of the differences in these populations. This study had a higher prevalence of ART users (20.3\%) than what is reported
Table 1 Social demographic and clinical characteristics of women using hormonal contraceptives at Mulago Hospital Family Planning Clinic in Kampala, March-April 2017

\begin{tabular}{|c|c|c|}
\hline Variable & $\begin{array}{l}\text { Number } \\
(\mathrm{n}=384)\end{array}$ & $\begin{array}{l}\text { Percentage } \\
(\%)\end{array}$ \\
\hline \multicolumn{3}{|c|}{ Age (categorised at the median) } \\
\hline $18-28$ & 215 & 56 \\
\hline $29-49$ & 169 & 44 \\
\hline \multicolumn{3}{|l|}{ Median (IQR): 28 (18-49) } \\
\hline \multicolumn{3}{|l|}{ Education } \\
\hline No formal education & 14 & 3.6 \\
\hline Primary & 107 & 27.9 \\
\hline Secondary & 227 & 59.1 \\
\hline Tertiary & 36 & 9.4 \\
\hline \multicolumn{3}{|l|}{ Parity } \\
\hline $0-1$ & 99 & 25.8 \\
\hline Two or more & 285 & 74.2 \\
\hline \multicolumn{3}{|l|}{ Fasting blood sugar } \\
\hline Normal (<120 mg/dL) & 373 & 97.1 \\
\hline High ( $\geq 120 \mathrm{mg} / \mathrm{dL})$ & 11 & 2.9 \\
\hline \multicolumn{3}{|l|}{ History of hypertension } \\
\hline No & 370 & 96.3 \\
\hline Yes & 14 & 3.7 \\
\hline \multicolumn{3}{|l|}{ Body mass index (BMI) } \\
\hline$\leq 25$ & 244 & 63.5 \\
\hline$>25$ & 140 & 36.5 \\
\hline \multicolumn{3}{|l|}{ Antiretroviral therapy use } \\
\hline No & 306 & 79.7 \\
\hline Yes & 78 & 20.3 \\
\hline \multicolumn{3}{|l|}{ Hormonal contraceptive used } \\
\hline Progestin-only pill & 5 & 1.3 \\
\hline Combined oral pill & 38 & 9.9 \\
\hline Progestin-only injectable & 185 & 48.2 \\
\hline $\begin{array}{l}\text { Combined Injectable } \\
\text { Contraceptive (CIC) }\end{array}$ & 8 & 2.1 \\
\hline Implant (one rod) & 124 & 32.3 \\
\hline Implant (two rods) & 24 & 6.2 \\
\hline \multicolumn{3}{|l|}{$\begin{array}{l}\text { Duration of use of } \\
\text { hormonal contraceptive }\end{array}$} \\
\hline$<6$ months & 124 & 32.3 \\
\hline 6-11 months & 41 & 10.7 \\
\hline$\geq 12$ months & 219 & 57 \\
\hline
\end{tabular}

in the general population (less than $5 \%$ ). ${ }^{11}$ Since ART use is associated with dyslipidaemias, the high prevalence obtained could have been as a result of the high percentage on ART.

The presence of dyslipidaemias in HC users has been reported by several other studies which found significant changes in the lipid profile levels of HC users. ${ }^{561419}$ These 
Table 2 Prevalence of dyslipidaemias according to social demographic and clinical characteristics of women using hormonal contraceptives at Mulago Hospital Family Planning Clinic in Kampala, March-April 2017

\begin{tabular}{|c|c|c|c|c|}
\hline Variable & $\begin{array}{l}\text { Dyslipidaemias } \\
\text { present, n (\%) }\end{array}$ & $\begin{array}{l}\text { No dyslipidaemias, } n \\
(\%)\end{array}$ & $\begin{array}{l}\text { Prevalence ratio } \\
(95 \% \mathrm{Cl})\end{array}$ & $P$ values \\
\hline $\begin{array}{l}\text { Overall prevalence of } \\
\text { dyslipidaemias }\end{array}$ & $243(63.3)$ & $141(36.7)$ & 58.4 to 68.1 & \\
\hline \multicolumn{5}{|c|}{ Age (categorised at the median) } \\
\hline $18-28$ & $128(59.5)$ & $87(40.5)$ & 1 & \\
\hline $29-49$ & $115(68.0)$ & $54(32.0)$ & 1.14 (0.98 to 1.32$)$ & 0.083 \\
\hline \multicolumn{5}{|l|}{ Median=28 (18-49) } \\
\hline \multicolumn{5}{|l|}{ Education } \\
\hline No formal education & $6(42.9)$ & $8(57.1)$ & $0.68(0.37$ to 1.25$)$ & 0.21 \\
\hline Primary & $66(61.7)$ & $41(38.3)$ & 0.97 (0.81 to 1.16$)$ & 0.759 \\
\hline Secondary & $144(63.4)$ & $83(36.6)$ & 1 & \\
\hline Tertiary & $27(75.0)$ & $9(25.0)$ & $1.18(0.96$ to 1.46$)$ & 0.124 \\
\hline \multicolumn{5}{|l|}{ Parity } \\
\hline $0-1$ & $59(59.6)$ & $40(40.4)$ & 1 & \\
\hline$\geq 2$ & $184(64.6)$ & $101(35.4)$ & 1.08 (0.90 to 1.30$)$ & 0.394 \\
\hline \multicolumn{5}{|l|}{ Fasting blood sugar } \\
\hline Normal & $234(62.7)$ & $139(37.3)$ & 1 & \\
\hline High & $9(81.8)$ & $2(18.2)$ & $1.30(0.98$ to 1.74$)$ & 0.072 \\
\hline \multicolumn{5}{|l|}{ History of hypertension } \\
\hline No & $235(63.5)$ & $135(36.5)$ & 1 & \\
\hline Yes & $8(57.1)$ & $6(42.9)$ & 0.90 (0.57 to 1.43$)$ & 0.653 \\
\hline \multicolumn{5}{|l|}{ Body mass index } \\
\hline$\leq 25$ & $138(56.6)$ & $106(43.4)$ & 1 & \\
\hline$>25$ & $105(75.0)$ & $35(25.0)$ & $1.33(1.15$ to 1.53$)$ & $<0.001$ \\
\hline \multicolumn{5}{|l|}{ Antiretroviral therapy use } \\
\hline No & $186(60.8)$ & $120(39.2)$ & 1 & \\
\hline Yes & $57(73.1)$ & $21(26.9)$ & $1.20(1.02$ to 1.41$)$ & 0.026 \\
\hline \multicolumn{5}{|c|}{ Hormonal contraceptive used } \\
\hline Oral contraceptives & $22(51.2)$ & $21(48.8)$ & 1.77 (0.57 to 1.05$)$ & 0.1 \\
\hline Injectables & $128(66.3)$ & $65(33.7)$ & 1 & \\
\hline Implants & $93(63.8)$ & $55(35.2)$ & $0.95(0.81$ to 1.11$)$ & 0.508 \\
\hline \multicolumn{5}{|c|}{ Duration of use of hormonal contraceptive } \\
\hline $77(62.1)$ & $47(37.9)$ & 1 & & \\
\hline $6-11$ months & $22(53.7)$ & $19(45.2)$ & 0.86 (0.63 to 1.19$)$ & 0.366 \\
\hline$\geq 12$ months & $144(65.8)$ & 75 (33.6) & 1.06 (0.90 to 1.25$)$ & 0.504 \\
\hline
\end{tabular}

changes in the lipid profile levels can be attributed to the lipogenic effect of oestrogen in which liver lipogenesis is increased and results in elevated levels of triglycerides and LDL levels. ${ }^{20}$ Furthermore, the progestin component of HCs increases hepatic lipase enzyme activity which increases the removal of HDL, hence decreasing the serum HDL levels. ${ }^{21}$

The factors significantly associated with dyslipidaemias in women using HCs were BMI and ART use. Participants who had a BMI greater than $25 \mathrm{~kg} / \mathrm{m}^{2}$ were $33 \%$ more likely to have dyslipidaemias compared with those who had a BMI of $25 \mathrm{~kg} / \mathrm{m}^{2}$ or less. This is in line with the findings from a systematic review by Halperin and colleagues in 2011. Halperin et $a l$ s study reported that differences in average BMI of women in the individual cohorts explained a portion of the heterogeneity found in High Density LipoproteinCholesterol (HDL-C) levels. ${ }^{7}$ These changes can be attributed to BMI independently affecting lipid profile levels as reported by studies which observed a significant association between high BMI and the occurrence of dyslipidaemias. ${ }^{22}{ }^{23}$ A study by Shamai and colleagues reported a significant association between 
Table 3 Multivariate analysis of the factors associated with dyslipidaemias in women using hormonal contraceptives at Mulago Hospital Family Planning Clinic in Kampala, MarchApril 2017

\begin{tabular}{llll}
\hline Variable & $\begin{array}{l}\text { Prevalence } \\
\text { ratio }\end{array}$ & $\mathbf{9 5 \%} \mathbf{~ C l}$ & P values \\
\hline $\begin{array}{l}\text { Body mass } \\
\text { index } \\
\leq 25\end{array}$ & 1 & & \\
$>25$ & 1.33 & 1.15 to 1.54 & $<0.001$ \\
$\begin{array}{l}\text { Antiretroviral } \\
\text { therapy use }\end{array}$ & & & \\
\hline No & 1 & & \\
\hline Yes & 1.21 & 1.03 to 1.42 & 0.02 \\
\hline
\end{tabular}

BMI and both triglyceride and HDL levels which was attributed to insulin resistance. ${ }^{23}$

ART use was the other factor associated with dyslipidaemias in women using HCs. Women who were using ART were $21 \%$ more likely to have dyslipidaemias than those who were not. This is one of the first studies to report on dyslipidaemias in ART users on HCs; therefore, there are no studies with which to compare our results. These changes in lipid profile levels can be attributed to some ART regimens exerting distinct alterations in lipid metabolism, hence bringing about dyslipidaemias. ${ }^{13}$ A study by Bekolo and colleagues in 2014 demonstrated a high prevalence of dyslipidaemias in patients with HIV infection on first-line ART in Cameroon. ${ }^{12}$

Some of the strengths of this study are: this is one of the first studies assessing dyslipidaemias in women using HCs to be carried out in Uganda. This contributes to further understanding and possibly, better management of dyslipidaemias in women using HCs. In addition, standardised approaches were used when carrying out this study, and this permits the study to be replicated in different areas or over time with an assurance that the results produced will have comparable findings.

We acknowledge the following limitations. The findings of this study may not be generalisable to all $\mathrm{HC}$ users because the sample is not representative enough. The sampling procedure used was non-probability, and this does not allow equal opportunity to all women to participate. As this was a cross-sectional study, a causal relationship cannot be established between HC use and dyslipidaemias. Since questionnaires were used for data collection, some of the self-reported information may have been inaccurate, hence affecting some of the results. Finally, information on the physical activity and diet of the study participants was not collected. This information is important since these variables play a significant role in changing lipid profile levels.

In conclusion, more than half the women using HCs had dyslipidaemias and are thus at an increased risk of acquiring cardiovascular diseases. HC users who had a BMI greater than $25 \mathrm{~kg} / \mathrm{m}^{2}$ and/or were on ART were more likely to have dyslipidaemias, and this in the long run increases their risk for cardiovascular disease.

We therefore recommend the Uganda Ministry of Health to formulate policy to better manage women using HCs. The policy should include checking lipid profile levels prior to initiation of HC use and also continued assessment at regular intervals while using contraceptives. The policy should in particular target the high-risk group that includes women whose BMI is greater than $25 \mathrm{~kg} / \mathrm{m}^{2}$ and/or are on ART. Further studies are urgently needed to explore whether the relationship between dyslipidaemias and HC use is causal.

Acknowledgements We would like to thank SURVIVAL PLUSS under the Norad Project (NORHED), the funders of this research. We acknowledge the Clinical Epidemiology Unit of Makerere University and the Mulago Hospital Family Planning Clinic staff and patient advisers.

Contributors RB conceptualised the study, designed it, planned the analysis, did the result interpretation and wrote the manuscript. She is the guarantor and responsible investigator of the study. PB-K planned and supervised the study, interpreted results and reviewed the manuscript. JKT planned the study, contributed in acquisition of funds, interpreted results and revised the manuscript. JNK planned and supervised the study and analysis and interpreted results. GN, IN, GSN and F0: planned the study and contributed in analysis. CK conceptualised, planned and supervised the study, interpreted results and reviewed the manuscript. All authors have read the final manuscript.

Funding The SURVIVAL-PLUSS under the Norhed project funded this research, Grant number: UGA-13-0030. Financing of research and management of funds.

Competing interests None declared.

Patient consent Not required.

Ethics approval Ethical approval was obtained from the School of Medicine Research Ethics Committee and the Uganda National Council for Science and Technology. Administrative clearance was obtained from the Research and Ethics Committee of Mulago National Referral Hospital.

Provenance and peer review Not commissioned; externally peer reviewed.

Data sharing statement All available data can be obtained by contacting the corresponding author.

Open access This is an open access article distributed in accordance with the Creative Commons Attribution Non Commercial (CC BY-NC 4.0) license, which permits others to distribute, remix, adapt, build upon this work non-commercially, and license their derivative works on different terms, provided the original work is properly cited, appropriate credit is given, any changes made indicated, and the use is non-commercial. See: http://creativecommons.org/licenses/by-nc/4.0/.

\section{REFERENCES}

1. UNFPA. Annual report 2015. http://www.unfpa.org/annual-report2015.

2. UDHS. Millennium development goal indicators. $2011 \mathrm{http}: / / w w w$. ubos.org/onlinefiles/uploads/ubos/UDHS/UDHS2011.pdf.

3. Sabatini R, Cagiano R, Rabe T. Adverse effects of hormonal contraception. J. Reproduktionsmed. Endokrinol 2011;8:130-56.

4. Schueller PO, Feuring M, Sharkova Y, et al. Effects of synthetic progestagens on autonomic tone, neurohormones and C-reactive protein levels in young healthy females in reproductive age. Int $J$ Cardiol 2006;111:42-8.

5. Stocco B, et al. The effect of different contraceptive drugs on the lipid profile of Brazilian Women. Pharm Anal Acta 2013;04.

6. Berenson AB, Rahman M, Wilkinson G. Effect of injectable and oral contraceptives on serum lipids. Obstet Gynecol 2009;114:786-94.

7. Halperin IJ, Kumar SS, Stroup DF, et al. The association between the combined oral contraceptive pill and insulin resistance, dysglycemia and dyslipidemia in women with polycystic ovary syndrome: a systematic review and meta-analysis of observational studies. Hum Reprod 2011;26:191-201.

8. Okeke $U$, et al. Comparative effects of injectable and oral hormonal contraceptives on lipid profile. European Journal of Medicine 2011;2. 
9. Wei W, Li Y, Chen F, et al. Dyslipidaemia, combined oral contraceptives use and their interaction on the risk of hypertension in Chinese women. J Hum Hypertens 2011;25:364-71.

10. UBOS. Uganda demographic and health survey 2011. https:// dhsprogram.com/pubs/pdf/FR264/FR264.pdf.

11. UNAIDS. UNAIDS Country factsheets Uganda 2017, 2017.

12. Bekolo CE, Nguena MB, Ewane L, et al. The lipid profile of HIV-infected patients receiving antiretroviral therapy in a rural Cameroonian population. BMC Public Health 2014;14:236.

13. Souza SJ, Luzia LA, Santos SS, et al. Lipid profile of HIV-infected patients in relation to antiretroviral therapy: a review. Rev Assoc Med Bras 2013;59:186-98.

14. Asare GA, Santa S, Ngala RA, et al. Effect of hormonal contraceptives on lipid profile and the risk indices for cardiovascular disease in a Ghanaian community. Int $J$ Womens Health 2014;6:597-603.

15. Kish L. Survey Sampling. New York: John Wiley and Sons, Inc, 1965:78-94.

16. Machado RB, Bernardes CR, de Souza IM, et al. Is lipid profile determination necessary in women wishing to use oral contraceptives? Contraception 2013;87:801-5.
17. Hulley SB. Designing Clinical Research. 4 edn, 2013.

18. Stein J. Guidelines for the Diagnosis and Management of Dyslipidemias for Adults $\geq 18$ Years Old, 2008.

19. Sitruk-Ware RL, Menard J, Rad M, et al. Comparison of the impact of vaginal and oral administration of combined hormonal contraceptives on hepatic proteins sensitive to estrogen. Contraception 2007;75:430-7.

20. Faryal UR, Hajra BS. Lipid profile in females of reproductive age group using combined oral contraceptive pills. Gomal J Med Sci 2012;10:233-6.

21. Yesmin F. Lipid profile in oral contraceptives user women. Dinajpur Med Col J 2013;6:54-7.

22. Aziz J, Siddiqui NA, Siddiqui IA, et al. Relation of body mass index with lipid profile and blood pressure in young healthy students at Ziauddin Medical University. J Ayub Med Coll Abbottabad 2003;15:19-21.

23. Shamai L, Lurix E, Shen M, et al. Association of body mass index and lipid profiles: evaluation of a broad spectrum of body mass index patients including the morbidly obese. Obes Surg 2011;21:42-7. 